\title{
Multiple Resistance to Acetyl Coenzyme A Carboxylase and Acetolactate Synthase Inhibiting Herbicides in Tunisian Ryegrass Populations (Lolium rigidum)
}

\author{
Haifa Hajri ${ }^{1}$, Yosra Menchari ${ }^{2}$ and Abdelwahed Ghrobel ${ }^{1}$ \\ 1. Center of Biotechnology of Borj Cedria, University of Tunis El Manar, BP 901 Hammam-Lif 2050, Tunisia \\ 2. Higher Institute of Biotechnology of Béja, University of Jendouba, Avenue Habib Bourguiba, BP 382, Béja 9000, Tunisia
}

\begin{abstract}
The good understanding of the mechanisms of resistance to herbicides in weeds is a necessity to implement sustainable weed management strategies. Here, a study was conducted to characterize the molecular bases of resistance to acetyl coenzyme A carboxylase (ACCase) and acetolactate synthase (ALS) inhibiting herbicides in Lolium rigidum populations from Tunisia. Nine Lolium rigidum (ryegrass) populations collected in wheat fields from Northern Tunisia were investigated for their resistance to two ACCase-inhibiting herbicides and an ALS-inhibiting herbicide. All populations were tested in the greenhouse in pots using the commercial dose to determine resistance status. Survival plants were also tested for the presence of two ACCase (L1781 and N2041) and two ALS (P197 and W574) mutant resistant alleles using molecular markers. Resistance to ACCase-inhibiting herbicides was found in all tested populations. Comparison of the results from herbicide sensitivity bioassays with genotyping indicated that more than $80 \%$ of the plants resistant to ACC-inhibiting herbicides would be resistant via increased herbicide metabolism. However, ALS-inhibiting herbicides are still more or less controlling ACCase resistant populations, so indicating that the selection process of resistance is ongoing. Target-site resistance appears to be the major mechanism for these early cases of ALS inhibitor resistance. This study reported the first case of resistance to ALS-inhibiting herbicides in ryegrass in Tunisia, and investigated the molecular bases of this resistance. It establishes the clear importance of non target-site resistance to ACCase- and/or ALS-inhibiting herbicides.
\end{abstract}

Key words: ACCase, ALS, cross resistance, Lolium, mutant resistant alleles, metabolism.

\section{Introduction}

In most agricultural areas worldwide, herbicides have become the major tool of weed control. The intense selection pressure exerted by herbicides has resulted in the development of herbicide resistance in many weed species as the consequence of the adaptive evolution of weed populations $[1,2]$.

Lolium rigidum (ryegrass) is one of the most troublesome herbicide-resistant weeds. It has evolved resistance to 11 herbicide modes of action [3]. Among herbicides having been selected for resistance in ryegrasses are acetolactate synthase (ALS, EC 2.2.1.6), also known as acetohydroxyacid-synthase (AHAS) inhibitors, and acetyl-CoA carboxylase (ACCase, EC

Corresponding author: Yosra Menchari, assistant professor, research field: plant biotechnology.

\subsubsection{2) inhibitors [4-9].}

ALS is the first common enzyme in the biosynthesis of leucine, isoleucine and valine [10]. ALS inhibitors are among the most used herbicides worldwide $[11,12]$. AHAS is the common target site of five AHAS-inhibiting herbicide chemistries, namely sulfonylurea (SU), imidazolinone (IMI), triazolopyrimidine, pyrimidinyl-thiobenzoates and sulphonyl-aminocarbonyltriazolinone.

Resistant weeds can survive from herbicide application via a variety of mechanisms that can be divided into two categories: target-site resistance (TSR) mechanisms, including increased expression of the target protein or structural changes to the herbicide binding site, and non-target-site resistance (NTSR) mechanisms, including any other mechanisms not belonging to TSR [13]. While the genetic basis of 
NTSR resistance is still obscure, TSR resistance is much better understood.

Resistance to ALS inhibitors can be due to mutations in the ALS gene that decreases the affinity of the ALS enzyme for herbicides, or to other mutations causing enhanced degradation of inhibitor molecules by plant metabolism [10]. A total of 22 resistance-endowing gene mutations at seven conserved amino acid residues in the ALS gene have so far been identified in field-evolved resistant weed biotypes [10,11, 14].

To date, mutations at Pro-197 (especially the Pro-197-Ser) and at Trp-574 are the most commonly reported [9, 14]. These two mutations confer resistance to SU and IMI families.

ACCase is a key enzyme in lipid biosynthesis that catalyzes the formation of malonyl-CoA from the carboxylation of acetyl-CoA. ACCase herbicides, introduced since 1978, have become widely used for grass weed control in world agriculture. There are many ACCase herbicides across the aryloxyphenoxypropionate (APP), cyclohexanedione (CHD) and phenylpyrazoline (PPZ) chemical groups. TSR results from a single amino acid change in the ACCase enzyme. To date, mutations at seven ACCase codons have been reported at positions 1781, 1999, 2027, 2041, 2078, 2088 and 2096 (Alopecurus myosuroides equivalent) $[10,15]$. The cross resistance patterns between currently commercial ACCase herbicides have been established in some weed species for some of these resistance mutations $[10,15]$.

The first case of ryegrass resistance to an ACCase herbicide was reported in 1982 in a wheat field in Australia [16]. Over the last 30 years, many more ryegrass populations have evolved resistance to ACCase-inhibiting herbicides across the five continents [2]. In Tunisia, the first case of herbicide resistance was reported in 1996. It concerned Lolium rigidum (ryegrass) populations collected in wheat fields from Northern Tunisia and found to be resistant to ACCase-inhibiting herbicides [17]. These herbicides have been broadly used to control grass weeds since the end of the $80 \mathrm{~s}$. As an alternative solution, farmers have come to rely on ALS-inhibiting herbicides and control failures have been observed, which suppose the development of ALS resistant Lolium populations.

The objective of this study was to investigate the molecular bases of resistance to ACCase- and ALS-inhibiting herbicides in nine Tunisian Lolium populations.

\section{Materials and Methods}

\subsection{Lolium Populations}

Nine populations of ryegrass (Lolium rigidum) were collected in 2009 from different wheat fields in Northern Tunisia (the governorate of Bizerte), where the first case of resistance to ACCase-inhibiting herbicides was reported in 1996 [17]. Seeds were randomly sampled from a large number of surviving plants across the entire field.

In the absence of a susceptible population, an Italian population displaying $20 \%$ of resistance to clodinafop and susceptible to ALS-inhibiting herbicides was used as a control. Resistance level was previously screened using a quick test experiment with Petri dishes containing agar and herbicide solution. No specific permissions were required for the locations where ryegrass seeds were collected.

\subsection{Whole-Plant Herbicide Sensitivity Assessment}

Seeds from each population were first placed in Petri-dishes containing a $\mathrm{KNO}_{3}$ solution $(20 \mathrm{mM})$ to increase germination rate, and incubated in a culture chamber at $18{ }^{\circ} \mathrm{C}$. Around 15 germinating seeds were sown at $2 \mathrm{~cm}$ deep in individual pots of $15 \mathrm{~cm}$ diameter containing a 1:1 ratio of sand and peat, and then irrigated as necessary. Pots were maintained in a controlled greenhouse set at $25{ }^{\circ} \mathrm{C}$ day for $16 \mathrm{~h}$ and $18{ }^{\circ} \mathrm{C}$ night for $8 \mathrm{~h}$. Seedlings at the two- to three-leaf stage were separately, and treated with the commercial's recommended application doses of the 

Herbicides in Tunisian Ryegrass Populations (Lolium rigidum)

commercial formulations of two ACCase-inhibiting herbicides, i.e., clodinafop-propargyl + cloquintocet-2-mexyl (Topik 100, 0.7 L/ha, Syngenta) and pinoxaden + clodinafop-propargyl (Traxos 45 EC, 1.2 L/ha, Syngenta), and an ALS-inhibiting herbicide, i.e., iodosulfuron + mesosulfuron (Amilcar, $30 \mathrm{~g} / \mathrm{ha}$, Bayer) using a moving nozzle sprayer at a rate of 200 $\mathrm{L} / \mathrm{ha}$. For each population investigated including the reference one, 15 additional plants were sprayed with water (untreated control). The pots were placed in a completely randomized design and three replicates were used for each treatment. Twenty-one days after treatment, the number of surviving plants in each pot was visually assessed for the ACCase inhibitors. As ALS-inhibiting herbicides causes stunt in grass weeds, the aboveground biomass was harvested, dried for $3 \mathrm{~d}$ at $65^{\circ} \mathrm{C}$ and weighted.

\subsection{Genotyping of ACCase and ALS Mutations}

A $1 \mathrm{~cm}$ section was cut from the first leaf of surviving seedlings in each population. Each leaf section was placed with a glass bead ( $2 \mathrm{~mm}$ diameter) into a $0.2 \mathrm{~mL}$ microcentrifuge tube containing $75 \mu \mathrm{L}$ of extraction buffer (100 mM Tris-HCl, $\mathrm{pH}=9.5,1 \mathrm{M}$ $\mathrm{KCl}, 10 \mathrm{mM}$ ethylenediaminetetraacetic acid (EDTA)).
Leaf fragments were disrupted using a bead mill TissueLyser (Qiagen, Courtaboeuf, France). Tubes were placed in a water bath at $95{ }^{\circ} \mathrm{C}$ for $6 \mathrm{~min}$, transferred onto ice for $5 \mathrm{~min}$ and vortexed for $15 \mathrm{~s}$. DNA extracts were diluted 50 -fold and kept at $-20^{\circ} \mathrm{C}$ before genotyping.

Published markers have been used as described in Refs. [4, 18, 19] to accurately detect the L1781 and N2041 ACCase mutations and P197 and W574 ALS mutations in Tunisian ryegrass populations (Table 1). All PCR amplifications were performed in $20 \mu \mathrm{L}$ reaction mixes [18]. Primers were used at $0.2 \mu \mathrm{M}$ each (Table 1). Cycling programs consisted of $95{ }^{\circ} \mathrm{C}$ for 5 min, followed by 37 cycles of $95{ }^{\circ} \mathrm{C} 5 \mathrm{~s}$, annealing temperature for $10 \mathrm{~s}$ and $72{ }^{\circ} \mathrm{C}$ for $30 \mathrm{~s}$ each. For cleaved amplifed polymorphic sequence (CAPS) and derived cleaved amplifed polymorphic sequence (dCAPS) techniques, digestions were performed for 3 $\mathrm{h}$ at $37{ }^{\circ} \mathrm{C}$, except for ApaI enzyme $\left(30^{\circ} \mathrm{C}\right)$. The 10 $\mu \mathrm{L}$ digestion mixes contained $4 \mu \mathrm{L}$ of the PCR mixes, $5 \mathrm{U}$ enzyme (Fermentas, Vilnius, Lithuania), $0.5 \mu \mathrm{L}$ $10 \times$ provided enzyme buffer and $4 \mu \mathrm{L}$ water. Patterns were visualized by electrophoresis on $3 \%(\mathrm{w} / \mathrm{v})$ agarose gels for CAPS and dCAPS and 1.3\% agarose gels for allele-specific PCR, run in $0.5 \mathrm{TBE}$ buffer.

Table 1 Primers and markers used for detection of ACCase and ALS mutant resistant alleles.

\begin{tabular}{|c|c|c|c|c|c|c|}
\hline Gene & Mutation & Primers** & Sequence 5 '-3' & $\begin{array}{l}\text { Annealing } \\
\text { temperature }\end{array}$ & $\begin{array}{l}\text { Restriction } \\
\text { enzyme }\end{array}$ & Technique \\
\hline \multirow{8}{*}{ ACCase } & \multirow{4}{*}{ Leu-1781* } & VRDIC+ & GGACTAGGTGTGGAGAACC & \multirow{4}{*}{$63^{\circ} \mathrm{C}$} & \multirow[t]{4}{*}{ j } & \multirow{4}{*}{$\begin{array}{l}\text { Gene-specific } \\
\text { PCR [18] }\end{array}$} \\
\hline & & VRDITR & CAATAGCAGCACTTCCATGTAA & & & \\
\hline & & ACVRG1 & AATGGGTCGTGGGGCACTCCTATAATTCC & & & \\
\hline & & ACVRG1R & GCTGAGCCTCAATATATTAGAAACAAC & & & \\
\hline & \multirow{2}{*}{ Asn-2041 } & ACCF1 & CACAGACCATGATGCAGCTC & \multirow{2}{*}{$62{ }^{\circ} \mathrm{C}$} & \multirow{2}{*}{ EcoRI } & \multirow{2}{*}{ CAPS [19] } \\
\hline & & ACCR1 & CTCCCTGGAGTTGTGCTTTC & & & \\
\hline & \multirow{2}{*}{ Gly-2078 } & ACCF1 & CACAGACCATGATGCAGCTC & \multirow{2}{*}{$62{ }^{\circ} \mathrm{C}$} & \multirow{2}{*}{ EcoRV } & \multirow{2}{*}{ dCAPS [19] } \\
\hline & & EcoRV2078r & GCACTCAATGCGATCTGGATTTATCTTGATA & & & \\
\hline \multirow{9}{*}{ ALS } & \multirow{3}{*}{ Pro-197 } & RG197F & TCCTCGACTCCATCCCCATGGTGGCCATCACG & \multirow{3}{*}{$60^{\circ} \mathrm{C}$} & \multirow{3}{*}{ Apa I } & \multirow{3}{*}{ dCAPS [4] } \\
\hline & & & GGGCAGGGC & & & \\
\hline & & RG197R & GCGGCCAGAGGAGGCGAGGAAGAAGG & & & \\
\hline & \multirow{3}{*}{ Trp-574 } & RG574F & GGTGATGATACTGAACAATCAACATCTTGGA & \multirow{3}{*}{$65^{\circ} \mathrm{C}$} & \multirow{3}{*}{ BstXI } & \multirow{3}{*}{ dCAPS [4] } \\
\hline & & & ATGCCAGTGCAG & & & \\
\hline & & ALV7R & ATACACCAGCATCATGCTGATCAGG & & & \\
\hline & \multirow{3}{*}{ Ser-653 } & RG653F & ATCATCGTCCCTCACCAGGAGCATGTGCTGC & \multirow{3}{*}{$60^{\circ} \mathrm{C}$} & \multirow{3}{*}{ Bpu10I } & \multirow{3}{*}{ dCAPS [4] } \\
\hline & & & CTATGATCCTT & & & \\
\hline & & ALV7R & ATACACCAGCATCATGCTGATCAGG & & & \\
\hline
\end{tabular}

*Amino acid positions correspond to the full length in Alopecurus myosuroides.

**Primer name ending with $\mathrm{F}$ (forward primer) and $\mathrm{R}$ (reverse primer). 


\subsection{Statistical Analysis}

Data were subjected to ANOVA to test significant differences between the resistant and the sensitive populations in response to each herbicide treatment using the PROC GLM statement in SAS (version 9.3, SAS Institute, Cary, NC).

\section{Results}

\subsection{Resistance Confirmation Test}

Screening of Lolium populations collected from wheat fields showed that there were very high frequencies of populations that are resistant to the ACCase-inhibiting herbicides. For clodinafop, a significant difference between the nine populations collected and the reference population used as a control was observed. The percentage of survivors varies between $31 \%$ and $94 \%$ (Fig. 1). The population used as a reference has a rate of $17 \%$ of surviving plants, not significantly different from the control level of $20 \%\left(\mathrm{Khi}^{2}=3.84, P=3.3 \mathrm{E}^{-8}\right)$. For the test with clodinafop + pinoxaden, only one population was sensitive. The other eight populations are displaying high frequencies of surviving plants varying between $38 \%$ and $100 \%$ (Fig. 1).

For the ALS-inhibiting herbicide, significant biomass reductions of $47 \%$ and $54 \%$ were observed in populations $\mathrm{P} 4$ and $\mathrm{P} 8$, respectively, compared to the

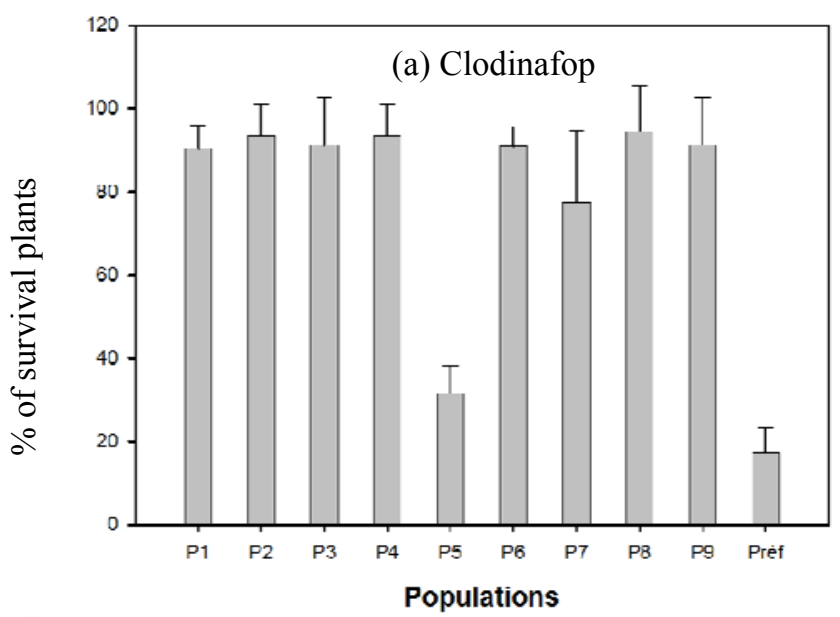

Fig. 1 Sensitivity of the 10 ryegrass populations to clodinafop percentage of survival plants.
Italian standard population (Fig. 2).

3.2 Molecular Bases of Resistance to ACCase- and ALS-Inhibiting Herbicides

Within the carboxyl-transferase (CT) domain of the plastidic ACCase gene, published markers were used to detect L1781 and N2041 mutations. In previous studies, these mutations are the most frequently observed in different grass weed species [19, 20].

The L1781 mutation was detected in eight out of the nine Lolium populations studied. Among the 124 surviving plants analyzed, 10 plants were homozygous mutant (8.1\%), 29 were heterozygous mutant (23.4\%) and 85 were wild type (68.5\%) (Table 2).

For the N2041 mutation, a total of 71 plants were genotyped. Three plants were homozygous mutant (4.2\%), 14 were heterozygous mutant (19.7\%) and 54 were wild type (76.1\%) (Table 2). The mutant resistant alleles were detected in five populations (P2, P3, P4, P6 and P8).

A total of 260 plants from the nine ryegrass populations were genotyped to detect the presence of P197 and W574 mutations. For the P197 mutation, three plants were homozygous mutant (1.2\%), 20 were heterozygous mutant $(7.7 \%)$ and 237 were wild type (91.1\%) (Table 2). It was detected in five populations and was the most prevalent in the population P4. For the W574 mutation, two plants were homozygous

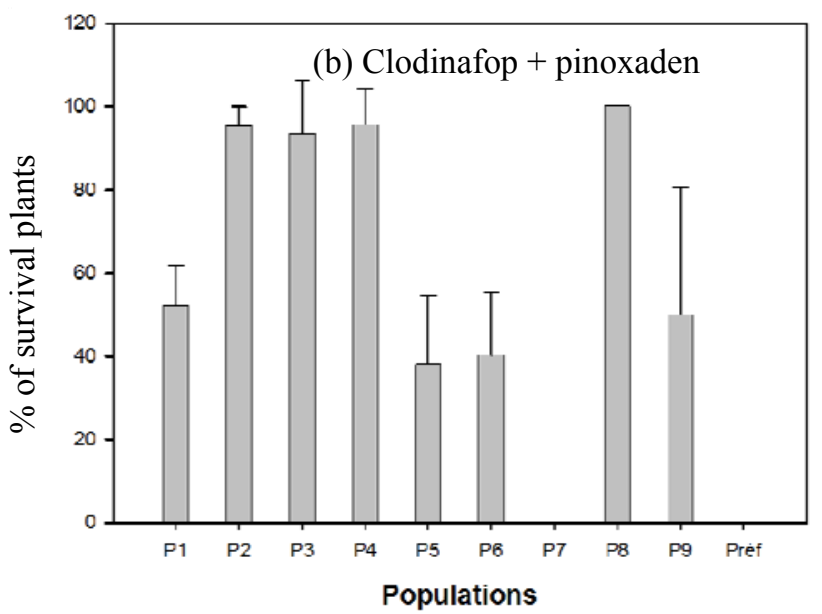

(a) and to clodinafop + pinoxaden (b) estimated by the 


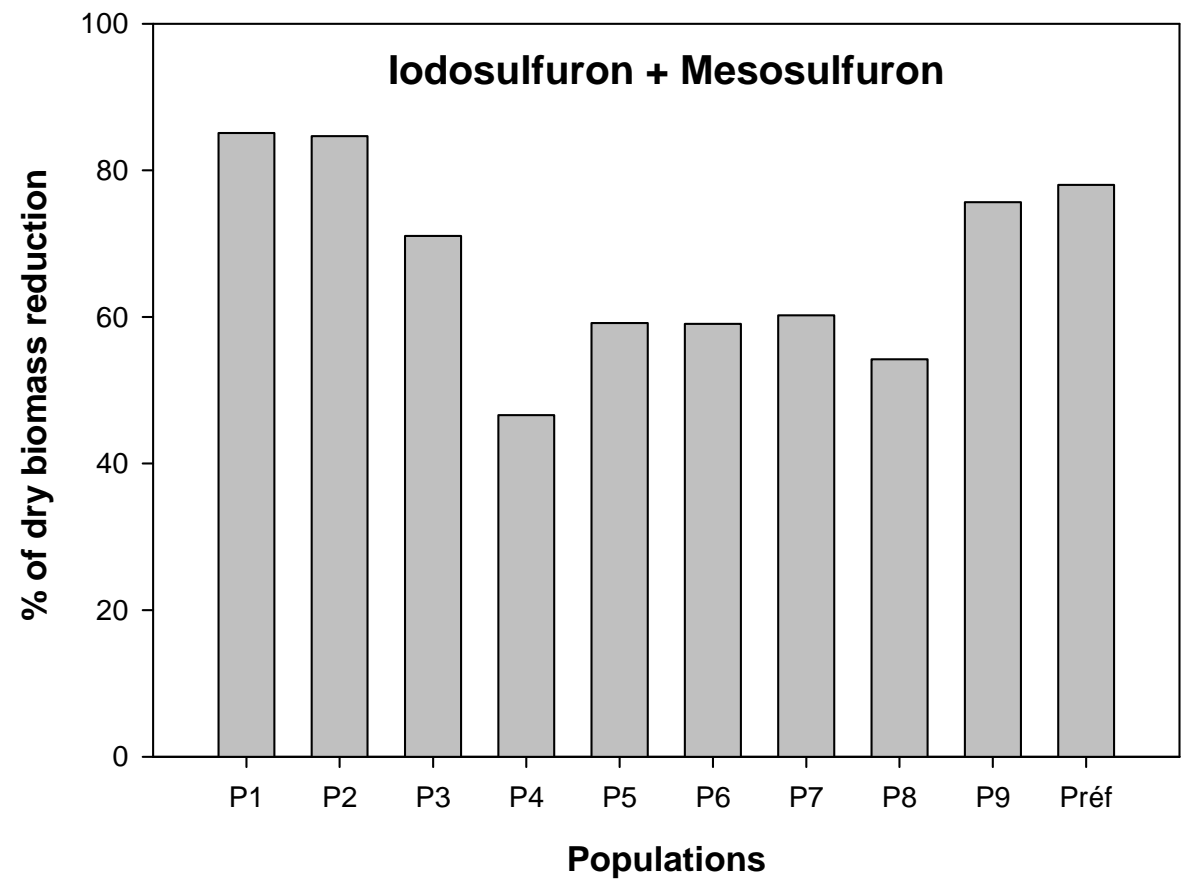

Fig. 2 Sensitivity of the 10 ryegrass populations to iodosulfuron + mesosulfuron estimated by the percentage of reduction of biomass related to the untreated control.

Table 2 Molecular analysis for plants in the Lolium populations investigated for ACCase and ALS resistant alleles.

\begin{tabular}{|c|c|c|c|c|c|c|c|c|c|c|c|c|c|c|c|c|}
\hline \multirow{3}{*}{ Variable } & \multicolumn{8}{|c|}{ ACCase alleles } & \multicolumn{8}{|c|}{ ALS alleles } \\
\hline & \multicolumn{4}{|c|}{ L1781 } & \multicolumn{4}{|c|}{ N2041 } & \multicolumn{4}{|c|}{ P197 } & \multicolumn{4}{|c|}{ W574 } \\
\hline & RR & $\mathrm{RS}$ & SS & Total & $\mathrm{RR}$ & $\mathrm{RS}$ & SS & Total & $\mathrm{RR}$ & $\mathrm{RS}$ & $\mathrm{SS}$ & Total & RR & $\mathrm{RS}$ & SS & Total \\
\hline No. of plants & 10 & 29 & 85 & 124 & 3 & 14 & 54 & 71 & 3 & 20 & 237 & 260 & 2 & 12 & 246 & 260 \\
\hline Frequency $(\%)$ & 8.1 & 23.4 & 68.5 & 100.0 & 4.2 & 19.7 & 76.1 & 100.0 & 1.2 & 7.7 & 91.2 & 100.0 & 0.8 & 4.6 & 94.6 & 100.0 \\
\hline
\end{tabular}

RR for homozygous mutant plants, RS for heterozygote and SS for wild-type.

mutant $(0.8 \%), 12$ were heterozygous mutant $(4.6 \%)$ and 246 were wild type (94.6\%) (Table 2). It was detected in five populations.

Different mutant alleles can be present within the same Lolium population. In this study, seven populations (P1, P2, P3, P4, P7, P8 and P9) contain at least one ACCase and one ALS mutant resistant alleles studied. In the P2 and P8 populations, the four alleles studied were detected.

\section{Discussion}

This is the first study to investigate the molecular bases of resistance to ACCase- and ALS-inhibiting herbicides in Tunisian Lolium populations, and the first to report resistance to ALS-inhibiting herbicides. Assessment of the sensitivity of nine ryegrass populations to two ACCase-inhibiting herbicides revealed that resistance is very developed. In Tunisia, these herbicides were broadly used for the control of grass weeds in cereal crops, which explain the high levels of resistance observed. It has been observed that the average number of resistant plants was weakly correlated with the number of applications of ACCase inhibitors [21, 22].

High levels of resistance have been observed with clodinafop + pinoxaden. The PPZ herbicide pinoxaden has been used in Tunisian wheat field since 2009 (the year when the author collected the populations), which indicates that resistant individuals to this herbicide were already present in the field and selected by other ACCase-inhibiting herbicides. A study conducted on Alopecurus myosuroides Huds. in France, where 
resistance to pinoxaden have been observed, showed that the average frequency of resistant plants computed for pinoxaden also increased with the number of clodinafop applications [22]. Similar results were also obtained on Italian Lolium populations [19]. This is consistent with the genotyping results in this study. In fact, in Lolium rigidum, the L1781 resistant alleles confer cross resistance to all APP, CHD and PPZ herbicides [10]. This mutation was detected in almost all populations studied.

The assessment of the sensitivity of the nine ryegrass populations showed that resistance to ALS-inhibiting is less developed than resistance to ACCase-inhibiting herbicides, and seems to be emerging. It has so far been detected in five countries [18], but this study represents the first report of this resistance in Tunisian Lolium populations.

Resistance to ACCase- and ALS-inhibiting herbicides was both observed within Tunisian Lolium populations. Biotypes that are resistant to herbicides from two or more mode-of-action families as conferred by more than one physiological mechanism are termed multiple herbicide resistant (MHR) [23]. This type of resistance makes weed management more challenging, because changing to a different mode of action may not control MHR biotypes. Besides, at least two different mutant alleles (ACCase and/or ALS alleles) were detected in the same population. This is to be expected in this highly genetically diverse, obligate cross-pollinated grass weed.

By computing the cross resistance patterns of L1781 and 2041 ACCase alleles, P197 and W574 ALS alleles and their respective frequencies in each population determined by genotyping, the expected proportions of plants to be resistant to clodinafop and iodosulfuron + mesosulfuron, respectively, were obtained. The comparison between these expected proportions with the observed ones obtained from pot bioassays revealed an excess of observed resistant plants to clodinafop in the nine Lolium populations. The ACCase alleles explain less than $20 \%$ of the resistance observed in ryegrass populations. The other part can mainly be due to NTSR. However, the mutant ALS resistant alleles account for most of the resistance to sulfonylurea.

NTSR is now considered the predominant type of resistance to the first and second most important herbicide groups worldwide, i.e. ACCase and ALS inhibitors in grasses [13]. For ryegrass, it was shown that an increased activity of a P450 conferred cross-resistance to ALS-inhibiting herbicides and ACCase-inhibiting herbicides [24].

\section{Conclusions}

This study has confirmed the presence of high levels of resistance to ACCase-inhibiting herbicides and reported for the first time resistance to ALS inhibitors in ryegrass Tunisian populations. However, this resistance is partly due to TSR. NTSR seems to be very widespread. It is a very complex phenomenon that cross resistance patterns could be in some cases very unpredictable and involve a wide range of herbicides that have even not yet used, thus complicating weed management. As a result, in the context of the dearth of innovation and increases of resistance, a herbicide becoming ineffective because of resistance is increasingly difficult to replace, and each herbicide molecule available is very valuable and should therefore be used as long as possible with a maximum of efficiency.

Considering the likelihood of multiple and NTSR resistance mechanisms in the same population, the implementation of integrated weed management practices will increasingly need to complement chemical means.

\section{Acknowledgments}

The first and second authors equally contribute to this work. The authors are grateful to the National Institute of Field Crops (INGC) team for their help in carrying out the sampling and harvesting, and to Fanny Pernin from the National Institute of Agronomic 

Herbicides in Tunisian Ryegrass Populations (Lolium rigidum)

Research (INRA) of Dijon for assistance in genotyping.

\section{References}

[1] Jasieniuk, M., Brûlé-Babel, A. L., and Morrison, I. N. 1996. "The Evolution and Genetics of Herbicide Resistance in Weeds." Weed Sci. 44 (1): 176-93.

[2] Neve, P., Vila-Aiub, M., and Roux, F. 2009. "Evolutionary-Thinking in Agricultural Weed Management." New Phytol. 184 (4): 783-93.

[3] Heap, I. 2015. "International Survey of Herbicide-Resistant Weeds." Accessed November 6, 2015. http://www.weedscience.com.

[4] Délye, C., Boucansaud, K., Pernin, F., and Le Corre, V. 2009. "Variation in the Gene Encoding Acetolactate-Synthase in Lolium Species and Proactive Detection of Mutant, Herbicide-Resistant Alleles." Weed Res. 49 (3): 326-36.

[5] Kaundun, S. S. 2010. "An Aspartate to Glycine Change in the Carboxyl Transferase Domain of Acetyl CoA Carboxylase and Non-Target-Site Mechanism(s) Confer Resistance to ACCase Inhibitor Herbicides in a Lolium multiflorum Population." Pest Manag. Sci. 66 (11): 1249-56.

[6] Scarabel, L., Panozzo, S., Varotto, S., and Sattin, M. 2011. "Allelic Variation of the ACCase Gene and Response to ACCase-Inhibiting Herbicides in Pinoxaden Resistant Lolium spp..” Pest Manag. Sci. 67 (8): 932-41.

[7] Martins, B. A., Sánchez-Olguín, E., Perez-Jones, A., Hulting, A. G., and Mallory-Smith, C. 2014. "Alleles Contributing to ACCase-Resistance in an Italian Ryegrass (Lolium perenne ssp. multiflorum) Population from Oregon." Weed Sci. 62 (3): 468-73.

[8] Tan, M. K., Preston, C., and Wang, G. X. 2007. "Molecular Basis of Multiple Resistance to ACCase-Inhibiting and ALS-Inhibiting Herbicides in Lolium rigidum." Weed Res. 47 (6): 534-41.

[9] Yu, Q., Han, H., Vila-Aiub, M., and Powles, S. B. 2010. "AHAS Herbicide Resistance Endowing Mutations: Effect on AHAS Functionality and Plant Growth." J. Exp. Bot. 61 (14): 3925-34.

[10] Powles, S., and Yu, Q. Q. 2010. "Evolution in Action: Plants Resistant to Herbicides.” Annu. Rev. Plant Biol. 61: 317-47.

[11] Tranel, P. J., and Wright, T. R. 2002. "Resistance of Weeds to ALS-Inhibiting Herbicides: What Have We Learned?" Weed Sci. 50 (6): 700-12.

[12] Corbett, C. A., and Tardif, F. J. 2006. "Detection of Resistance to Acetolactate Synthase-Inhibiting in Weeds with Emphasis on DNA-Based Techniques: A Review." Pest Manag. Sci. 62 (7): 584-97.

[13] Délye, C. 2013. "Unravelling the Genetic Bases of
Non-Target-Site-Based Resistance (NTSR) to Herbicides: A Major Challenge for Weed Science in the Forthcoming Decade.” Pest Manag. Sci. 69 (2): 176-87.

[14] Tranel, P. J., Wright, T. R., and Heap, I. M. 2009. “ALS Mutations from Herbicide-Resistant Weeds." Accessed November 6, 2015. http://www.weedscience.org.

[15] Délye, C. 2005. "Weed Resistance to Acetyl Coenzyme A Carboxylase Inhibitors: An Update." Weed Sci. 53 (5): 728-46.

[16] Heap, I., and Knight, R. 1982. "A Population of Ryegrass Tolerant to the Herbicide Diclofop-Methyl." J. Austra. Inst. of Agri. Sci. 48 (3): 156-7.

[17] Souissi, T., Labidi, S., and Ben Haj Salah, H. 2004. "Highlighting and Origin of Herbicide Resistant Ryegrass in Wheat Crops." Rev. INAT 18: 149-61. (in French)

[18] Délye, C., Matéjicek, A., and Gasquez, J. 2002. "PCR-Based Detection of Resistance to Acetyl-CoA Carboxylase-Inhibiting Herbicides in Blackgrass (Alopecurus myosuroides Huds.) and Ryegrass (Lolium rigidum Gaud.)." Pest Manag. Sci. 58 (5): 474-8.

[19] Yu, Q., Collavo, A., Zheng, M. Q., Owen, M., Sattin, M., and Powles, S. B. 2007. "Diversity of Acetyl-Coenzyme A Carboxylase Mutations in Resistant Lolium Populations: Evaluation Using Clethodim.” Plant Physiol. 145 (2): 547-58.

[20] Menchari, Y., Camilleri, C., Michel, S., Brunel, D., Dessaint, F., Le Corre, V., and Délye, C. 2006. "Weed Response to Herbicides: Regional-Scale Distribution of Herbicide Resistance Alleles in the Grass Weed Alopecurus myosuroides." New Phytol. 171 (4): 861-74.

[21] Délye, C., Menchari, Y., Guillemin, J. P., Matéjicek, A., Michel, S., Camilleri, C., and Chauvel, B. 2007. "Status of Blackgrass (Alopecurus myosuroides) Resistance to Acetyl-Coenzyme A Carboxylase in France." Weed Res. 47 (2): 95-105.

[22] Petit, C., Bay, G., Pernin, F., and Délye, C. 2010. "Prevalence of Cross or Multiple Resistance to the Acetyl-Coenzyme A Carboxylase Inhibitors Fenoxaprop, Clodinafop and Pinoxaden in Blackgrass (Alopecurus myosuroides Huds.) in France." Pest Manag. Sci. 66 (2): 168-77.

[23] Hall, L. M., Holtum, J. A. M., and Powles, S. B. 1994. "Mechanisms Responsible for Cross Resistance and Multiple Resistance." In Herbicide Resistance in Plants: Biology and Biochemistry, edited by Powles, S. B., and Holtum, J. A. M. Boca Raton, FL: Lewis Publishers, 243-61.

[24] Preston, C., Tardif, F. J., Christopher, J. T., and Powles, S. B. 1996. "Multiple Resistance to Dissimilar Herbicide Chemistries in a Biotype of Lolium rigidum Due to Enhanced Activity of Several Herbicide Degrading Enzymes." Pestic. Biochem. Physiol. 54 (2): 123-34. 